\title{
Enzymes involved in mammalian oligosaccharide biosynthesis
}

\author{
Shunji Natsuka and John B Lowe
}

\author{
Howard Hughes Medical Institute and University of Michigan Medical School, Ann Arbor, USA
}

\begin{abstract}
Several new sialyltransferases, $\mathrm{N}$-acetylgalactosaminyltransferase and fucosyltransferase genes have been reported in this past year. These sequences have advanced our understanding of the structural, functional and evolutionary relationships amongst the glycosyltransferases, including their roles in selectin ligand biosynthesis. Ablation of the murine $\mathrm{N}$-acetylgalactosaminyltransferase I gene through gene 'knock out' technology has yielded insight into the role of this gene in the developing mouse. Novel 'O-linked' protein glycosylation events described in the past year have added to the substantial known diversity in the oligosaccharide structure and glycosyltransferase repertoire of mammalian organisms.
\end{abstract}

Current Opinion in Structural Biology 1994, 4:683-691

\section{Introduction}

Eukaryotic organisms synthesize oligosaccharide chains through the actions of glycosyltransferases, coupled with oligosaccharide-chain remodeling events catalyzed by glycohydrolases. These latter enzymes, including glucosidases and mannosidases, for example (reviewed in [1]), typically operate during the early stages of protein $N$-glycoside maturation (Fig. 1). By contrast, both early and late stages of oligosaccharide chain synthesis require glycosyltransferases [2-4]. With few exceptions, each glycosyltransferase can catalyze the synthesis of a single glycosidic linkage. Because recent work has indicated that multiple distinct enzymes can synthesize identical sugar linkages, there must be roughly a few hundred distinct glycosyltransferases, and corresponding genes, to synthesize the multitude of distinct oligosaccharides identified in mammalian species.

Molecular cloning efforts initiated in 1986 [5-7] have to date yielded the discovery and characterization of more than 30 different mammalian glycosyltransferase genes

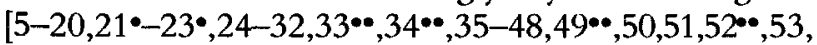
$\left.54^{\bullet \bullet}, 55^{\bullet \bullet}, 56^{\bullet}\right]$. Each of the glycosyltransferase genes or cDNAs cloned to date predict enzymes with a common topology, consisting of a short (less than 25 residues) amino-terminal cytoplasmic domain, a single transmembrane segment, and a larger carboxyl-terminal catalytic domain (generally more than 325 residues) in the lumen of the Golgi apparatus. Several Golgi oligosaccharideprocessing enzymes also share this type II transmembrane topology, suggesting that this topology has an important function in these Golgi-resident proteins. Some, though not all, mammalian glycosyltransferases are themselves subject to post-translational processing by glycosylation; many are also processed into soluble forms through proteolytic events.

Despite the topological similarity of these glycosyltransferases, sequence analysis of cloned enzymes suggests that there is generally little, if any, detectable primary sequence similarity between members of enzymatically distinct glycosyltransferase families, although glycosyltransferases within rather small catalytically related families may share primary sequence similarity. There are, for example, no discernible significant primary sequence similarities between the human $\mathrm{H}$ blood group $\alpha(1,2)$ fucosyltransferase [25] (GDP-fucose: $\beta$ $D$-galactoside $2-\alpha-L-f u c o s y l t r a n s f e r a s e)$ and any of the $\alpha(1,3)$ fucosyltransferases $\left[33^{\bullet \bullet, 34 \bullet \bullet}\right.$ (GDP-fucose: $\beta$-D$\mathrm{N}$-acetylglucosaminide 3- $\alpha$-L-fucosyltransferases), despite the fact that these two classes use the nucleotide sugar substrate GDP-fucose, and can operate on identical oligosaccharide precursor substrates. By contrast, the $\alpha(1,3)$ fucosyltransferases share substantial amounts of primary sequence similarity. This review summarizes recent progress in the structural and functional definition of mammalian glycosyltransferases through molecular cloning approaches. We also discuss recent results obtained through genetic 'knock out' of the murine $N$-acetylglucosaminyltransferase-I gene, which encodes a key enzyme in the synthesis of complex type asparagine-linked glycosides. Current understanding of the relationship between selectin ligand synthesis and

\section{Abbreviations}

EGF-_epidermal growth factor; ELFT_ELAM-1 ligand fucosyltransferase; Fuc-T_fucosyltransferase; GlcNAC-T-I—N-acetylglucosaminyltransferase-I; PCR — polymerase chain reaction. 


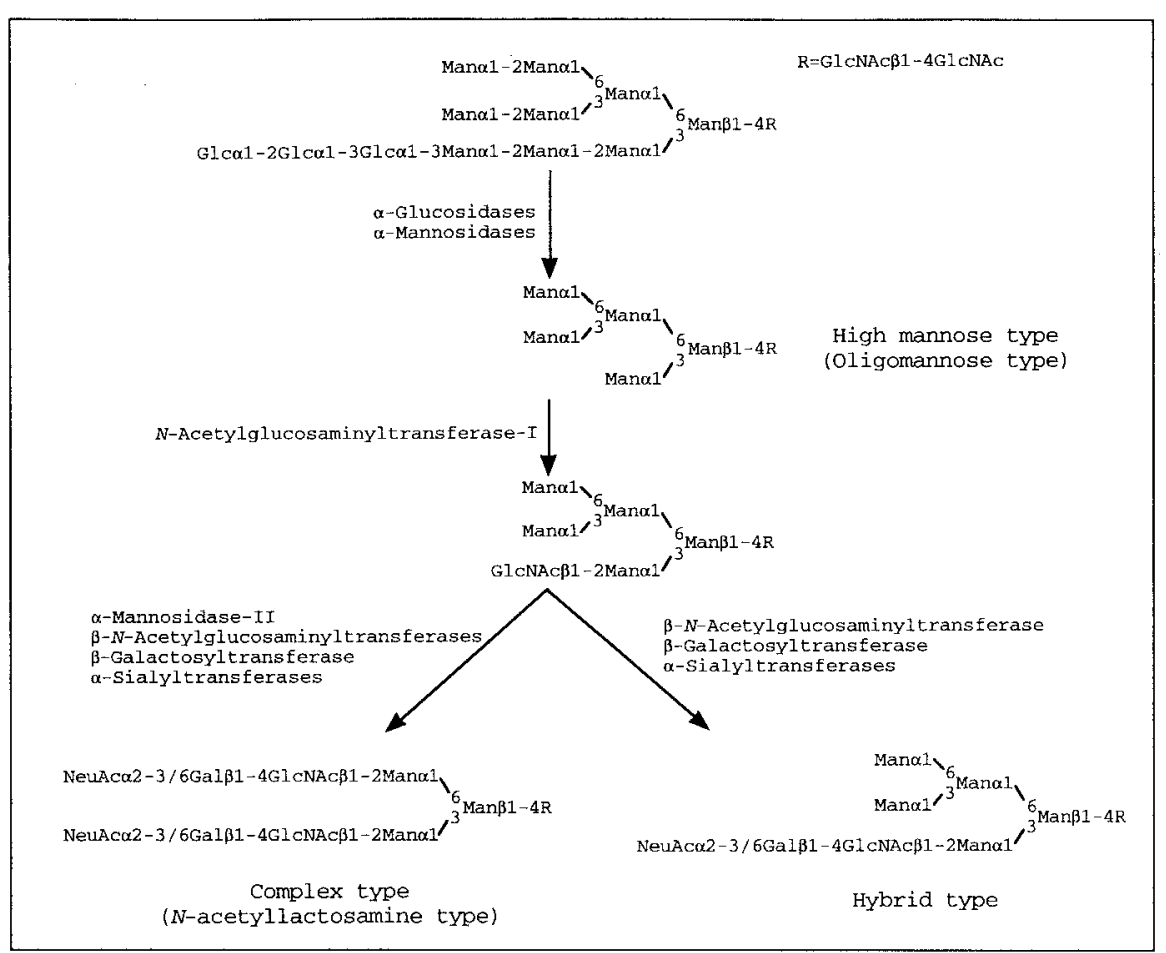

Fig. 1. The biosynthesis of N-linked oligosaccharides. Representative examples of each type are shown; microheterogeneity within each structural example yields many more structures than are shown here. $\alpha(1,3)$ fucosyltransferases is outlined, with a discussion of recently described novel protein glycosylation modifications.

\section{Recently isolated glycosyltransferase genes}

Since the glycosyltransferases are generally non-abundant proteins, it has been difficult to purify these enzymes for molecular cloning purposes. Cloning methods have therefore been developed to allow the isolation of glycosyltransferase genes without the need for protein purification (reviewed in [3-5]). These include expressioncloning approaches, low-stringency hybridization methods, and polymerase chain reaction (PCR) cloning with primers derived from sequences conserved in catalytically similar glycosyltransferases. An expression cloning method originally developed by Seed et al. $[57,58]$ (see also [59]) has been applied, with some modification, to glycosyltransferase cloning $[15,24,26,29,34 \bullet \cdot, 39,42,43]$. This approach generally involves the screening of mammalian cDNA expression libraries transfected into a mammalian host cell, using a genetic selection or screen for a novel glycosylation phenotype. Selections or screens rely on antibodies or lectins capable of detecting a novel surface-localized glycosidic modification corresponding to the glycosyltransferase of interest. Although this method can select directly for a functional cDNA, its successful use requires host cells with the proper glycosylation phenotype (i.e. competent in the synthesis of the desired enzyme's precursor substrates, but deficient in the desired enzyme itself), and reagents that can detect, or select for, the oligosaccharide product of the desired enzyme.
Rapid and technically straightforward low-stringency hybridization methods have also been used to isolate new members of gene families encoding catalytically similar glycosyltransferases $\left[28,30,32,33^{\circ} \cdot\right]$. This approach cannot be expected to yield genes corresponding to glycosyltransferases with catalytic properties distinct from the probe enzyme, however, because interfamily sequence comparisons suggest that these enzymes will maintain primary sequences virtually entirely distinct from the probe sequence. PCR cloning approaches have been used to circumvent this difficulty in some instances, where previous sequence comparisons have identified short conserved sequence motifs amongst a group of enzymes with shared, and distinct, catalytic properties.

\section{Sialyltransferases}

Biochemical experiments have indicated that mammalian organisms may encoded numerous sialyltransferases. Sequence analysis of the first several cloned sialyltransferases identified a conserved peptide motif in these enzymes (Fig. 2), embedded within otherwise dissimilar protein sequences. Paulson and co-workers [48] used this observation to design oligodeoxynucleotide PCR primers with degenerate sequences corresponding to the ends of the 'sialyl' motif [45]. These primers were then used with the PCR to amplify novel sequences from cDNA libraries. In one instance, this approach yielded a PCR product with a novel sequence, from a human placenta cDNA library. A cDNA subsequently isolated from the library with the PCR product was shown by sequence analysis and expresson studies to encode a novel $\alpha(2,3)$ sialyltransferase, termed STZ [54*0]. 
The enzyme STZ can efficiently sialylate both glycoprotein and glycolipid substrates, to form the terminal sequences NeuAc $\alpha 2-3 \mathrm{Gal} \beta 1-3 \mathrm{GalNAc}$ and NeuAc 2 23GalB1-4GlcNAc. This enzyme cannot form the product NeuAc 2 2-3GalB1-3GlcNAc, nor can it operate on terminal Lewis $\mathbf{x}$ or Lewis a trisaccharide determinants to form sialyl Lewis $\mathrm{x}$ or sialyl Lewis a moieties. These results lend additional support to previous observations (cited in [28]) indicating that $\alpha 2-3$ sialylation precedes a regulated $\alpha 1-3$ fucosylation event in the ordered synthetic process of these two selectin ligands.

The Paulson group have also used this PCR approach to isolate another novel CDNA, termed STX, from a newborn rat brain cDNA library [49*0]. The cDNA sequence predicts a protein with a type II topology and primary structure consistent with those of other sialyltransferases. However, attempts to demonstrate that the recombinant protein manifests sialyltransferase activity have failed so far, even though a relatively wide variety of acceptor substrates have been tested. Nonetheless, it is very interesting that the STX gene is transcribed in newborn rat brain, but not in the adult brain, nor in other organs, including the kidney, liver, spleen, intestine, submaxillary gland and lung. These observations suggest that this putative sialyltransferase may play a critical role in the developing central nervous system, an organ where substantial metabolic activity is devoted to ganglioside biosynthesis.

Tsuji and collaborators [55•*] also used the PCR method to isolate novel sialyltransferase genes, including a chicken GalNAc $\alpha 2,6$-sialyltransferase sequence and two distinct murine and rat $\alpha(2,3)$ sialyltransferase genes $\left[51,56^{\circ}\right]$. One of the products of the chicken sialyltransferase is the sialyl Tn determinant (NeuAco26GalNAc $\alpha 1-\mathrm{Ser} / \mathrm{Thr}$ ). This antigen has been identified in mammalian species as a 'cancer-related' epithelial cell antigen, and should be interesting to explore the expression, regulation, and function of the human counterpart(s) of this gene in human carcinomas.

One of the murine $\alpha(2,3)$ sialyltransferases cloned by Tsuji et al. (ST3GalA.1) [55*0] is apparently the homologue of a porcine submaxillary gland $\mathrm{Gal} \beta 1,3 \mathrm{Gal} N A \mathrm{c} \alpha-$ 2,3 sialyltransferase reported previously [47]. The other $\alpha(2,3)$ sialyltransferases, isolated from both mouse and rat, are novel Gal $\beta 1,3 \mathrm{GalNAc} \alpha(2,3)$ sialyltransferases (ST3GalA.2). Although ST3GalA.1 and ST3GalA.2 exhibit roughly similar acceptor substrate specificities, they maintain distinct tissue-specific expression patterns. The ST3GalA.1 gene is abundantly expressed in submaxillary glands, for example, whereas the $S T 3 \mathrm{GalA} .2$ transcripts are most prominent in the mouse brain and liver.

Sasaki et al. [52.0] have recently reported the use of a modified expression-cloning method in the isolation of a human Gal $\beta 1,3 / 1,4 \mathrm{GlcNAc} \alpha 2,3$-sialyltransferase gene. These investigators used a cytotoxic lectin [Ricinus communis agglutinin $\left(\mathrm{RCA}_{120}\right)$, which binds to $\beta$-galactosides], to select for a cDNA encoding a sialyltransferase that extensively masks the surface-localized $\beta$-galactoside toxin receptors on the transfected, lectin-susceptible mammalian host. The resulting cloned cDNA encodes an $\alpha(2,3)$ sialyltransferase capable of using both GalB1-3GlcNAc and Galß1-4GlcNAc. The sequence of this enzyme is essentially identical to the $\alpha(2,3)$ sialyltransferase cloned by Kitagawa and Paulson [54*0], who reported that this enzyme is unable to use Galp1-3GlcNAc. This discrepancy has not yet been resolved.

\section{$\mathrm{N}$-acetylgalactosaminyltransferases}

Synthesis of O-linked oligosaccharides on cell surface and secreted proteins is initiated by the covalent modification of some serines or threonines with $\mathrm{N}$ acetylgalactosamine. This reaction is catalyzed by one (or possibly more) UDP-GalNAc:polypeptide $\mathrm{N}$-acetylgalactosaminyltransferases. Two groups have independently reported the isolation of cDNA clones encoding the bovine form of a UDP-GalNAc:polypeptide $N$-acetylgalactosaminyltransferase purified from bovine colostrum, and expressed in the small intestine [22.] or placenta [23*]. This enzyme is predicted to maintain the type II transmembrane topology typical of other glycosyltransferases. Initial characterization of the acceptor substrate specificy of the recombinant form of the enzyme indicates that it transfers GalNAc to threonine residues at a rate more than 50 -fold greater than transfer to serine residues in similar peptide sequence con-
$\operatorname{hST} 3(\mathrm{G} 3 / 4 \mathrm{GN})$

mST3 (G3GalNAC) - I

mST3 (G3GalNAC) - II

hST3 (G4GN/3GalNAC)

CST6 (GalNAC)

hST6 (G4GN)

rSTX (?)

\begin{abstract}
157 GRBC I I VGNG

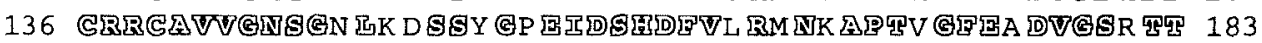

149 CRREA VW

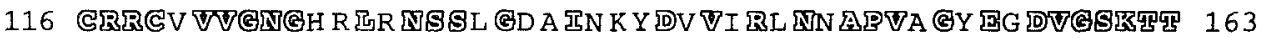

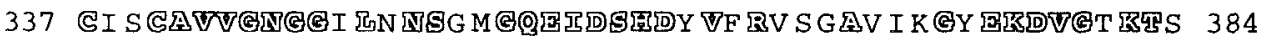

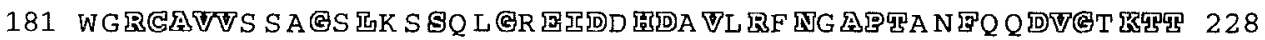

154 FQT
\end{abstract}

Fig. 2. Comparison of amino acid sequences of sialyltransferases in the 'sialylmotif'. Their substrate specificities are shown in parenthesis: $\mathrm{G}$, galactose; $\mathrm{GN}, \mathrm{N}$-acetylglucosamine. Numbers on their names indicate linkage positions of glycosidic bonds. References are (from top): hST3(G3/4GN), [45]; mST3(G3GalNAc)-I, [46]; mST3(G3GalNAc)-II, [51]; hST3(G4GN/3GalNAc), [49••]; cST6(GalNAc), [50]; hST6(G4GN), [40]; rSTX, [44]. Amino acids conserved in any three sequences are emphasized by outlined letters. 
texts $\left[22^{\bullet}, 23^{\bullet}\right]$. These observations suggest the existence of additional UDP-GalNAc:polypeptide $N$-acetylgalactosaminyltransferases.

An expression-cloning approach has been used recently to isolate a murine cDNA encoding a $\beta(1,4) N$-acetylgalactosaminyltransferase that operates on glycoproteins with the terminal oligosaccharide NeuAc $\alpha 2,3 \mathrm{Gal} \beta 1,4-$ GlcNAc $\beta 1,3 \mathrm{Gal}\left[21^{\circ}\right]$. This enzyme forms an oligosaccharide epitope defined previously as the human $\mathrm{Sd}^{a}$ blood group antigen $[\mathrm{NeuAc} \alpha 2,3(\mathrm{Gal} N A c \beta 1,4) \mathrm{Gal} \beta 1,4$ GlcNAc $\beta 1,3 \mathrm{Gal}]$. This latter antigen has also been defined independently as a functionally significant epitope (known as CT1 or CT2) on murine cytotoxic T cells. This murine CT $\beta(1,4) N$-acetylgalactosaminyltransferase shares a substantial degree of primary sequence similarity with a previously cloned human $\beta(1,4) N$-acetylgalactosaminyltransferase that creates a glycolipid antigen known as GM2 [20]. GM2 and the Sda antigen share the identical terminal tetrasaccharide moiety, but differ in their underlying substructure (glycolipid versus glycoprotein, respectively). An analysis of these two enzymes should provide information on their peptide sequences that allow discrimination between substrates with identical trisaccharide termini presented on otherwise dissimilar molecules. It will also be interesting to see whether the human Sda blood group locus corresponds to the mouse sequence, and to explore the functional role of the CT1/CT2 epitope in immune cells.

\section{Ablation of the GlcNAc transferase-I gene in mice}

The gene targeting method developed by Capecchi $e t$ al. $[60,61]$ is a powerful technique that is widely used to study biological function(s) of molecules whose expression is regulated by a cloned gene. Two groups have independently used this approach to explore complex asparagine-linked ( $N$-linked) oligosaccharides. A key regulatory step in the biosynthesis of these molecules is catalyzed by the glycosyltransferase termed $\mathrm{N}$ acetylglucosaminyltransferase-I (GlcNAc-T-I; the product of the mgat-I locus; Fig. 1) $[35,36,38]$. These investigators created mice deficient in the GlcNAc-T-I gene through standard gene targeting procedures $\left[62^{\bullet \bullet}, 63^{\bullet \bullet}\right]$. Mice heterozygous for one null mgat-I allele develop normally, and are without any obvious abnormal phenotype. By contrast, homozygosity for the null mgat-1 allele yields a lethal embryonic phenotype. These mice die at approximately 11.5 days of gestation. Homozygous null embryos have no detectable GlcNAcT-I activity, and are also (as expected) completely deficient in hybrid and complex type $N$-linked oligosaccharides. Blastocyst and morula formation, compaction and implantation proceed normally without GlcNAc-T-I expression, suggesting that complex and hybrid type $N$-linked oligosaccharides are not essential for early mouse development. Null embryos are growth-retarded, however, have less than the normal number of somites and exhibit a defect in neuropore closure. Approximately half of the homozygous null embryos also exhibit a phenotype known as situs inversus, which apparently results from an inversion of the normal developmental rotational process that yields organ asymmetry. The mechanisms responsible for each component of this pleiotropic phenotype are not yet understood. These may eventually be shown to include disruption of essential $\mathrm{N}$-linked oligosaccharidedependent cell-cell recognition events during mid-embryogenesis, or a requirement for $\mathrm{N}$-linked oligosaccharides in the proper folding, intracellular trafficking or turnover of developmentally important glycoproteins. In any event, most glycobiologists will be pleased that mature $N$-oligosaccharides (complex and hybrid types, at least) are necessary for proper mammalian development.

\section{Fucosyltransferases and selectin ligand biosynthesis}

Leukocyte adhesion to E- and P-selectins is an early and important step in the process of leukocyte extravasation. The sialyl Lewis $\mathrm{x}$ tetrasaccharide is an essential component of the counterreceptors for these two selectins (reviewed in $[64,65]$ ). The final step in the biosynthesis of the sialyl Lewis $\mathrm{x}$ tetrasaccharide is catalyzed by $\alpha(1,3)$ fucosyltransferases (Fuc-T) operating on $\alpha(2,3)$ sialylated $N$-acetyllactosamine type oligosaccharides [66] (Fig. 3). As noted above, there is as yet no precedent for an $\alpha(2,3)$ sialyltransferase activity capable of sialylating the Lewis $\mathrm{x}$ tetrasaccharide to form the sialyl Lewis $x$ antigen (Fig. 3).

Five distinct human $\alpha(1,3)$ fucosyltransferase genes have been cloned and characterized [26-32, 33*•,34*0] (Table 1). Two of these, termed Fuc-TIV and Fuc-TVII, are transcribed in HL-60 cells [67.] and other leukocyte cell lines that express selectin ligands $\left[27,28,33^{\bullet \bullet}, 34^{\bullet \bullet}\right]$. They are thus candidates for fucosyltransferases that control selectin-ligand biosynthesis in leukocytes. By contrast, transcripts corresponding to the Fuc-TIII, FucTV and Fuc-TVI genes are not generally expressed to a significant degree in these cells. These observations, and genetic analysis of the Fuc-TIII and Fuc-TVI loci, exclude these latter three genes from such consideration.

Fuc-TIV [28,29] is also known as ELFT (ELAM-1 ligand fucosyl transferase) [27]. Characterizations of the in vitro catalytic properties of Fuc-TIV/ELFT indicate that it does not efficiently form the sialyl Lewis $\mathrm{x}$ tetrasaccharide from 3 -sialyl $N$-acetyllactosamine. Likewise, FucTIV does not yield cell surface sialyl Lewis $\mathrm{x}$ expression when expressed in some cultured cell lines that can be converted to sialyl Lewis $\mathrm{x}$ positivity by transfection with other $\alpha(1,3)$ fucosyltransferase genes [28,29]. By contrast Goelz et al. [27] reported that Fuc-TIV/ELFT determines expression of E-selectin ligands and the sialyl Lewis $\mathrm{x}$ antigen when expressed in a dihydrofo- 


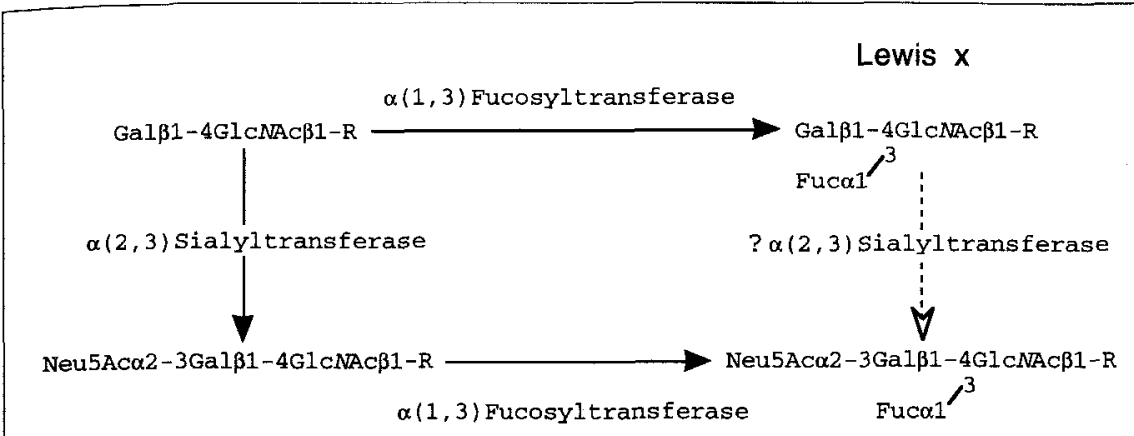

Sialyl Lewis $\mathbf{x}$
Fig. 3. The biosynthetic routes of the siaIyl Lewis $x$ determinant. The broken line indicates a hypothetical route that would require a sialyltranferase with activities not found in any known sialyltransferase. late reductase-resistant Chinese hamster ovary cell line. Goelz et al. [68*0] hypothesize that these discrepancies can be accounted for by differences in the glycosylation phenotype of host cells used in these types of transfection experiments. The biochemical basis of these differences is not yet known, nor is it known whether human leukocytes maintain a glycosylation phenotype capable of supporting Fuc-TIV-determined sialyl Lewis $\mathrm{x}$ expression.

The recent molecular cloning of another human $\alpha(1,3)$ fucosyltransferase gene, termed Fuc-TVII, suggests another, Fuc-TIV-independent, route for sialyl Lewis $\mathrm{x}$ expression in leukocytes $\left[33^{\circ \bullet}, 34^{\bullet \bullet}\right]$. The FucTVII gene is expressed in several types of cultured human leukocytic cell lines. In vitro, the corresponding enzyme can efficiently use sialyl $\mathrm{N}$-acetyllactosamine as an acceptor substrate to form the sialyl Lewis $\mathrm{x}$ tetrasaccharide. Furthermore, expression of this enzyme in COS-7 and Chinese hamster ovary cells leads to surface expression of the sialyl Lewis $\mathrm{x}$ antigen. Although these observations suggest two possible routes for the biosynthesis of $\mathrm{E}$ - and $\mathrm{P}$-selectin ligands, the relative contributions of these routes to this process remains to be explored, as does the possibility that there are other paths also, using other unknown enzymes.

\section{Novel $O$-linked oligosaccharides}

Many mammalian glycoproteins contain complex carbohydrates linked through O-glycosidic linkages to some serine or threonine residues (Fig. 4). Although the understanding of the O-glycoside biosynthesis is less advanced than that of $\mathrm{N}$-linked oligosaccharides, O-glycosides are believed to be as biologically important as the $\mathrm{N}$-glycosides. L- and P-selectin oligosaccharide ligands are born on $\mathrm{O}$-glycosides of mucin-like glycoproteins [69-75], for example, and GlcNAc moieties linked directly to serine or threonine residues on many nuclear and cytoplasmic proteins are thought to be important regulators of protein-protein interactions (reviewed in [76]; see also Hayes and Hart, pp 692-696).

Recent advances in analytical methods for oligosaccharide structures have led to the discovery of several novel types of O-glycosides. Hase et al. [77-80] (see also [81]) have recently reported a xylosylglucose type sugar chain found on several blood clotting glycoproteins (Fig. 4). Although $\beta$-linked xylose residues are widely distributed as a core residue on proteoglycans, the xylosylglycans reported by Hase $e t$ al. are the first examples of $\alpha$-linked xylose residues in mammalian glycoproteins. Each of

Table 1. Human $\alpha(1,3)$ fucosyltransferases.

\begin{tabular}{|c|c|c|c|c|c|}
\hline & Fuc-TIII & $\begin{array}{l}\text { Fuc-TIV } \\
\text { (ELFT) }\end{array}$ & Fuc-TV & Fuc-TVI & Fuc-TVII \\
\hline Classification & $\begin{array}{l}\text { Lewis blood } \\
\text { group type }\end{array}$ & Myeloid type & - & 'Plasma type' & Leukocyte type \\
\hline $\begin{array}{l}\text { Potential N- } \\
\text { glycosylation sites }\end{array}$ & 2 & 2 & 4 & 4 & 2 \\
\hline Human chromosome & 19 & $11 q 21$ & 19 & 19 & 9 \\
\hline Catalytic products & $\begin{array}{c}\text { Le }^{x}, \text { sLex, Lea, } \\
\text { sLe }{ }^{\mathrm{a}}, \text { VIM-2 }\end{array}$ & Lex, VIM-2 & Le $^{x}$, sLex, VIM-2 & $\operatorname{Le} x, \operatorname{se}^{x}$ & $\operatorname{sLe}^{x}$ \\
\hline References & {$[26]$} & {$[27-29,90]$} & {$[30]$} & {$[32]$} & {$[33,34]$} \\
\hline
\end{tabular}


the xylosylglucose-type oligosaccharides found to date occur on the epidermal growth factor (EGF)-like domains on clotting factors or structurally-related glycoproteins [77-80]. The $\alpha(1,3) x y$ losyltransferase(s) and/or peptide: $\alpha$-glucosyltransferases responsible for biosynthesis of these oligosaccharides are most probably expressed in hepatocytes, because the liver is the major site of synthesis of these particular coagulation factors. O-linked fucose residues have also been described on the EGF-like domains of some glycoproteins $\left[82-85,86 \bullet, 87^{\bullet \bullet}, 88^{\bullet \bullet}\right]$. The positions of attachment of fucose residues differ from the xylosylglucose attachment sites, and the spectrum of glycoproteins that display O-linked fucose residues differ from the set of proteins modified by xylosylglucose moieties [77-81]. Some of these O-linked fucose moieties are substituted with an $\mathrm{N}$-acetylglucosamine residue, which is in turn modified by galactose and then sialic acid $\left[87^{\bullet \bullet}, 88^{\bullet \bullet}\right.$ ] (Fig. 4). The enzymatic basis for synthesis of these structures is an exciting and unexplored area, which will certainly lead to the discovery of novel peptide: $\alpha$-fucosyltransferase, and related enzymes. The function(s) of these novel glycosidic structures also remains to be explored.

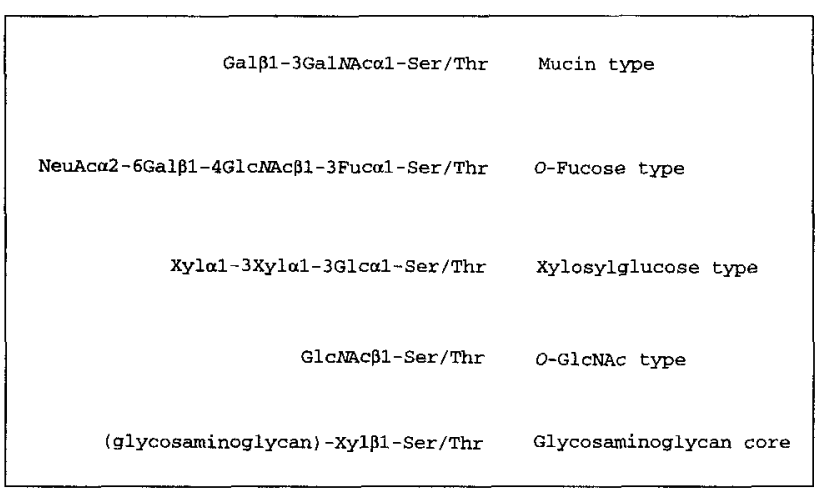

Fig. 4. Structures of $\mathrm{O}$-glycosides linked to serine or threonine residues. Numerous other mucin-type oligosaccharide structures have also been described.

\section{Future prospects and conclusions}

Given the large number of predicted mammalian glycosyltransferases, continued growth can be expected in the number of these enzymes for which structures and biochemistry are defined through molecular cloning efforts. While the approaches discussed here will certainly continue to be useful, it may be necessary to develop novel techniques to obtain new glycosyltransferase genes that cannot be cloned with existing methods. This might include cloning methods based on the selection of, or screening for, an enzyme activity, instead of using selections or screens that are dependent upon synthesis of a new surface carbohydrate determinant recognized by antibodies or lectins.
We can also expect to see the discovery of additional novel oligosaccharide structures, analagous to the $O$ fucose and xylosylglucose type $O$-glycosides discussed above. These advances will be made possible by the use of recently developed, highly sensitive, methods for oligosaccharide structural analysis. These methods include matrix-assisted laser desorption mass spectrometry, for example, which can analyze picomole amounts of sample $[89,90]$, and two-dimensional mapping of fluorescent-tagged sugar chains, which can detect femtomole amounts of glycoconjugate molecules $[91,92]$.

In conclusion, the emerging array of cloned oligosaccharide-processing enzyme genes, coupled with new analytical technologies and molecular genetic approaches to the study of oligosaccharide function (e.g. transgenesis and gene targeting), open a bright and exciting future for glycobiology.

\section{Acknowledgements}

This work was supported in part by NIH grant 1R01GM47455. John Lowe is an Associate Investigator of the Howard Hughes Medical Institute.

\section{References and recommended reading}

Papers of particular interest, published within the annual period of review have been highlighted as:

- of interest

-. of particular interest

1. Moreman KW, Trimble RB, Herscovics A: Glycosidases of the Asparagine-linked Oligosaccharide Processing Pathway. Glycobiology 1994,4:113-125.

2. Schachter $\mathrm{H}$ : Enzymes Associated with Glycosylation. Curr Opin Struct Biol 1991, 1:755-765.

3. Shaper IH, Shaper NL: Enzymes Associated with Glycosylation. Curr Opin Struct Biol 1992, 2:701-709.

4. van den Eijnden $\mathrm{DH}$, Joziasse $\mathrm{DH}$ : Enzymes Associated with Glycosylation. Curr Opin Struct Biol 1993, 3:711-721.

5. Narimatsu H, Sinha S, Brew K, Okayama H, Qasba PK: Cloning and Sequencing of CDNA of Bovine $N$-acetylglucosamine (B1-4)galactosyltransferase. Proc Natl Acad Sci USA 1986, 83:4720-4724.

6. Humphreys-Beher MG, Bunnell B, van Tuinen P, Ledbetter $\mathrm{DH}$, Kidd V]: Molecular Cloning and Chromosomal Localization of Human 4- $\beta$-galactosyltransferase. Proc Natl Acad SCi USA 1986, 83:8918-8922.

7. Shaper NL, Shaper JH, Bertness V, Chang H, Kirsch IR, Hollis GF: The Human Galactosyltransferase Gene is on Chromosome 9 at Band p13. Somat Cell Mol Genet 1986, 12:633-636.

8. Nakazawa $\mathrm{K}$, Ando T, Kimura T, Narimatsu $\mathrm{H}$ : Cloning and Sequencing of a Full-length cDNA of Mouse $\mathbf{N}$-acetylglucosamine (B1-4)galactosyltransferase. J Biochem 1988, 104:165-168.

9. Shaper NL, Hollis GF, Douglas JG, Kirsch IR, Shaper JH: Characterization of the Full Length CDNA for Murine B-1,4-galactosyltransferase. Novel Features at the 5'-end Predict Two Translational Start Sites at Two In-frame AUGs. J Biol Chem 1988, 263:10420-10428. 
10. Masri KA, Appert HE, Fukuda MN: Identification of the Full-length Coding Sequence for Human Galactosyltransferase ( $\beta$ - $N$-acetylglucosaminide: $\beta 1$,4-galactosyltransferase). Biochem Biophys Res Commun 1988, 157:657-663.

11. Shaper $\mathrm{H}$, Hollis GF, Shaper NL: Evidence for Two Forms of Murine B-1,4-galactosyltransferase Based on Cloning Studies. Biochimie 1988, 70:1683-1688.

12. D'Agostaro G, Bendiak B, Tropak M: Cloning of cDNA Encoding the Membrane-bound Form of Bovine B1,4-galactosyltransferase. Eur / Biochem 1989, 183:211-217.

13. Ghosh S, Basu SS, Basu S: Isolation of a cDNA Clone for B-1,4-galactosyltransferase from Embryonic Chicken Brain and Comparison to its Mammalian Homologs. Biochem Biophys Res Commun 1992, 189:1215-1222.

14. Joziasse $\mathrm{DH}$, Shaper $\mathrm{JH}$, Van den Eijnden $\mathrm{DH}$, Van Tunen A), Shaper NL: Bovine $\alpha 1$,3-galactosyltransferase: Isolation and Characterization of a cDNA Clone. Identification of Homologous Sequences in Human Genomic DNA. J Biol Chem 1989, 264:14290-14297.

15. Larsen RD, Rajan VP, Ruff MM, Kukowska-Latallo J, Cummings RD, Lowe JB: Isolation of a cDNA Encoding a Murine UDP-galactose: $\beta$-D-galactosyl-1,4- $N$-acetyl-D-glucosaminide $\alpha$ 1,3-galactosyltransferase: Expression Cloning by Gene Transfer. Proc Natl Acad Sci USA 1989, 86:8227-8231.

16. Dabkowski PL, Vaughan HA, McKenzie IF, Sandrin MS: Characterisation of a cDNA Clone Encoding the Pig $\alpha-1,3$-galactosyltransferase: Implications for Xenotransplantation. Transplant Proc 1993, 25:2921.

17. Schulte S, Stoffel W: Ceramide UDP-galactosyltransferase from Myelinating Rat Brain: Purification, Cloning and Expression. Proc Natl Acad Sci USA 1993, 90:10265-10269.

18. Yamamoto F, Marken J, Tsuji T, White T, Clausen H, Hakomori S: Cloning and Characterization of DNA Complementary to Human UDP-GalNAc: Fuc $\alpha-1,2-G a l \alpha 1-3-G a l N A c$ Transferase (Histo-blood Group A Transferase) mRNA. J Biol Chem 1990, 265:1146-1151.

19. Martinko JM, Vincek V, Klein D, Klein J: Primate ABO Glycosyltransferases: Evidence for Trans-species Evolution. Immunogenetics 1993, 37:274-278.

20. Nagata $Y$, Yamashiro S, Yodoi J, Lloyd KO, Shiku H, Furukawa $\mathrm{K}$ : Expression Cloning of $\mathrm{B}-1,4-\mathrm{N}$-acetylgalactosaminyltransferase cDNAs that Determine the Expression of $\mathrm{G}_{\mathrm{M2}}$ and $\mathrm{C}_{\mathrm{D} 2}$ Gangliosides. / Biol Chem 1992, 267:1 2082-12089.

21. Smith PL, Lowe JB: Molecular Cloning of a Murine $\mathrm{N}$-acetylgalactosamine-transferase cDNA that Determines Expression of the T lymphocyte-specific CT Oligosaccharide Differentiation Antigen. / Biol Chem 1994, 269:15162-15171.

A cDNA encoding a GalNAc-transferase capable of forming the $\mathrm{Sd}$ determinant [NeuAca2-3(GalNAcB-1,4)GalB1,4-GlcNAc; also known as $\mathrm{CT} 1$ and $\mathrm{CT} 2$ ] was isolated from a mouse cytotoxic T-cell line. The cytotoxic determinants are expressed on activated cytotoxic T cells, but not on naive $\mathrm{T}$ cells.

22. Homa FL, Hollander T, Lehman DJ, Thomsen DR, Elhammer

- AP: Isolation and Expression of a cDNA Clone Encoding a Bovine UDP-GalNAc:Polypeptide $\mathrm{N}$-acetylgalactosaminyltransferase. I Biol Chem 1993, 268:12609-12616.

A bovine CDNA was cloned that encodes a polypeptide GalNAC-transferase involved in mucin type O-glycoside synthesis. The transcripts are widely distributed in many organs.

23. Hagen FK, van Wuyckhuyse B, Tabak LA: Purification,

- Cloning and Expression of a Bovine UDP-GalNAc: Polypeptide N-acetyl-galactosaminyltransferase. I Biol Chem 1993, 268:18960-18965.

The authors molecular cloning of the same cDNA described in [22*]. This group also carried out in vitro enzyme assays using a panel of serine- or threonine-containing substrates.

24. Rajan VP, Larsen RD, Ajmera S, Ernst LK, Lowe JB: A Cloned Human DNA Restriction Fragment Determines Expression of a GDP-I-fucose: $\beta$-D-galactoside 2 - $\alpha$-L-fucosyltransferase in Transfected Cells. Evidence for Isolation and
Transfer of the Human H Blood Group Locus. / Biol Chem 1989, 264:11158-11167.

25. Larsen RD, Ernst LK, Nair RP, Lowe JB: Molecular cloning, Sequence and Expression of a Human GDP-I-fucose: B-D-galactoside 2- $\alpha-L$-fucosyltransferase cDNA that can Form the $H$ Blood Group Antigen. Proc Natl Acad Sci USA 1990, 87:6674-6678.

26. Kukowska-Latallo JF, Larsen RD, Nair RP, Lowe JB: A Cloned Human cDNA Determines Expression of a Mouse Stagespecific Embryonic Antigen and the Lewis Blood Group $\alpha(\mathbf{1}, \mathbf{3} / \mathbf{1}, \mathbf{4})$ fucosyltransferase. Genes Dev 1990, 4:1288-1303.

27. Goelz SE, Hession C, Goff D, Griffiths B, Tizard R, Newman B, Chi-Rosso G, Lobb R: ELFT: a Gene that Directs the Expression of an ELAM-1 Ligand. Cell 63:1349-1356.

28. Lowe JB, Kukowska-Latallo JF, Nair RP, Larsen RD, Marks RM, Macher BA, Kelly RJ, Ernst LK: Molecular Cloning of a Human Fucosyltransferase Gene that Determines Expression of the Lewis $x$ and VIM-2 epitopes but not ELAM-1-dependent Cell Adhesion. / Biol Chem 1991, 266:17467-17477.

29. Kumar R, Potvin B, Muller WA, Stanley P: Cloning of a Human $\alpha(1,3)$ fucosyltransferase Gene that Encodes ELFT but Does Not Confer ELAM-1 Recognition on Chinese Hamster Ovary Cell Transfectants. / Biol Chem 1991, 266:21777-21783.

30. Weston BW, Nair RP, Larsen RD, Lowe JB: Isolation of a Novel Human $\alpha(1,3)$ fucosyltransferase Gene and Molecular Comparison to the Human Lewis Blood Group $\alpha(1,3 / 1,4)$ fucosyltransferase Gene. Syntenic, Homologous, Non-allelic Genes Encoding Enzymes with Distinct Acceptor Substrate Specificities. / Biol Chem 1992, 267:4152-4160.

31. Koszdin KL, Bowen BR: The Cloning and Expression of a Human $\alpha-1,3-$ fucosyltransferase Capable of Forming the E-selectin Ligand. Biochem Biophys Res Commun 1992, 187:152-157.

32. Weston BW, Smith PL, Kelly RJ, Lowe JB: Molecular Cloning of a Fourth Member of a Human $\alpha(1,3)$ fucosyltransferase Gene Family. Multiple Homologous Sequences that Determine Expression of the Lewis $x$, Sialyl Lewis $x$ and Difucosyl Sialyl Lewis x Epitopes. I Biol Chem 1992, 267:24575-24584.

33. Natsuka S, Gersten KM, Zenita K, Kannagi R, Lowe JB: Molec- ular Cloning of a cDNA Encoding a Novel Human Leukocyte $\alpha(1,3)$ fucosyltransferase Capable of Synthesizing the Sialyl Lewis x Determinant. J Biol Chem 1994,269:16789-16794.

A cDNA was cloned that encodes a fucosyltransferase, which may play a pivotal role in the synthesis of E- and P-selectin ligands was isolated from the human natural killer cell line. The gene is also expressed in myeloid line $\mathrm{HL}-60$ and can form sialyl Lewis $\mathrm{x}$ determinant.

34. Sasaki K, Kurata K, Funayama K, Nagata M, Watanabe E, Ohta - $\quad S$, Hanai $N$, Nishi T: Expression Cloning of a Novel $\alpha 1,3$. fucosyltransferase that is Involved in Biosynthesis of the Sialyl Lewis $x$ Carbohydrate Determinants in Leukocytes. I Biol Chem 1994, 269:14730-14737.

A novel $\alpha 1,3$-fucosyltransferase cDNA was isolated by a sophisticated expression cloning method. The CDNA is the same as that reported in

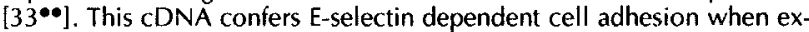
pressed in cultured cells.

35. Kumar R, Yang J, Larsen RD, Stanley P: Cloning and Expression of $\mathrm{N}$-acetylglucosaminyltransferase $\mathrm{I}$, the Medial Golgi Transferase that Initiates Complex N-linked Carbohydrate Formation. Proc Natl Acad Sci USA 1990, 87:9948-9952.

36. Sarkar M, Hull E, Nishikawa Y, Simpson RI, Moritz RL, Dunn R, Schachter $\mathrm{H}$ : Molecular Cloning and Expression of cDNA Encoding the Enzyme that Controls Conversion of High-mannose to Hybrid and Complex N-glycans: UDP-N-acetylglucosamine: $\alpha-3$-D-mannoside $\mathrm{B}-1,2-\mathrm{N}$-acetylglucosaminyltransferase I. ProC Natl Acad SCi USA 1991, 88:234-238.

37. Hull E, Sarkar M, Spruijt MP, Hoppener JW, Dunn R, Schachter $H$ : Organization and Localization to Chromosome 5 of the Human UDP-N-acetylglucosamine: $\alpha-3-D$-mannoside $\beta-1,2-N-$ acetylglucosaminyltransferase I Gene. Biochem Biophys Res Commun 1991, 176:608-615.

38. Pownall S, Kozak CA, Schappert K, Sarkar M, Hull E, Schachter $\mathrm{H}$ : Molecular Cloning and Characterization of 
the Mouse UDP- $N$-acetylglucosamine: $\alpha$-3-D-mannoside $\beta$ 1,2-N-acetylglucosaminyltransferase I Gene. Genomics 1992, 12:699-704.

39. Kumar R, Yang J, Eddy RL, Byers MG, Shows TB, Stanley P: Cloning and Expression of the Murine Gene and Chromosomal Location of the Human Gene Encoding $\mathrm{N}$-acetylglucosaminyltransferase I. Glycobiology 1992, 2:383-393.

40. Nishikawa $A$, Ihara $Y$, Hatakeyama $M$, Kangawa $K$, Taniguchi $\mathrm{N}$ : Purification, CDNA cloning and Expression of UDP$N$-acetylglucosamine: $\beta$-D-mannose $\beta 1,4 N$-acetylglucosaminyltransferase III from Rat Kidney. J Biol Chem 1992, 267:18199-18204.

41. Ihara $Y$, Nishikawa A, Tohma $T$, Soejima $H$, Niikawa $N$, Taniguchi N: cDNA Cloning, Expression and Chromosomal Localization of Human $\mathrm{N}$-acetylglucosaminyltransferase III (GnTIII). J Biochem 1993, 113:692-698.

42. Bierhuizen MF, Fukuda M: Expression Cloning of a CDNA Encoding UDP-GlcNAc:GalB1-3GalNAc-R (GlcNAc to GalNAc) B1-6GlcNAc Transferase by Gene Transfer into CHO Cells Expressing Polyoma Large Tumor Antigen. Proc Natl Sci USA 1992, 89:9326-9330.

43. Bierhuizen MF, Mattei MG, Fukuda M: Expression of the Developmental I Antigen by a Cloned Human cDNA Encoding a Member of a $\mathbf{B 1}, \mathbf{6 - N}$-acetylglucosaminyltransferase Gene Family. Genes Dev 1993, 7:468-478.

44. Weinstein J, Lee EU, MCEntee K, Lai PH, Paulson JC: Primary Structure of $\beta$-galactoside $\alpha 2,6$-sialyltransferase. Conversion of Membrane-bound Enzyme to Soluble Forms by Cleavage of the $\mathrm{NH}_{2}$-Terminal Signal Anchor. / Biol Chem 1987, 262:17735-17743.

45. Grundmann $U$, Nerlich C, Rein T, Zettlmeissl G: Complete cDNA Sequence Encoding Human $\beta$-galactoside $\alpha-2,6$-sialyltransferase. Nucleic Acids Res 1990, 18:667.

46. Bast BJEG, Zhou L-J, Freedman GJ, Colley KJ, Ernst TJ, Munro JM, Tedder TF: The HB-6, CDw75 and CD76 Differentiation Antigens are Unique Cell-surface Carbohydrate Determinants Generated by the $\beta$-galactoside $\alpha 2,6$-sialyltransferase. / Cell Biol 1992, 116:423-435.

47. Gillespie W, Kelm S, Paulson JC: Cloning and Expression of the Gal B1,3GalNAc $\alpha 2,3$-sialyltransferase. J Biol Chem 1992, 267:21004-21010.

48. Wen DX, Livingston BD, Medzihradszky KF, Kelm S, Burlingame $\mathrm{AL}$, Paulson JC: Primary Structure of Gal $\beta 1,3(4)$ GlcNAc $\alpha 2,3$ sialyltransferase Determined by Mass Spectrometry Sequence Analysis and Molecular Cloning. Evidence for a Protein Motif in the Ssialyltransferase Gene Family. J Biol Chem 1992, 267:21011-21019.

49. Livingston BD, Paulson JC: Polymerase Chain Reaction Cloning -. of a Developmentally Regulated Member of the Sialyltransferase Gene Family. I Biol Chem 1993, 268:11504-11507.

A cDNA homologous to the previously cloned sialyltransferase genes was cloned. Its transcript was found in newborn mouse brain, but not in adult brain. The protein encoded by the cDNA did not manifest detectable sialyltransferase activity when tested with several acceptor substrates.

50. Kitagawa $H$, Paulson JC: Cloning and Expression of Human Gal $\beta 1,3(4) G I c N A c \quad \alpha 2,3$-sialyltransferase. Biochem Biophys Res Commun 1993, 194:375-382.

51. Lee Y-C, Kurosawa N, Hamamoto T, Nakaoka T, Tsuji S: Molecular Cloning and Expression of Galß1,3GalNAc $\alpha 2,3$ sialyltransferase from Mouse Brain. Eur / Biochem 1993, 216:377-385.

52. Sasaki K, Watanabe E, Kawashima K, Sekine S, Dohi T, Oshima - $M$, Hanai N, Nishi T, Hasegawa M: Expression Cloning of a Novel Gal $\beta(1-3 / 1-4)$ GIcNAC $\alpha 2,3$-sialyltransferase using Lectin Resistance Selection. / Biol Chem 1993, 268:22782-22787.

A novel sialyltransferase CDNA was isolated with an expression cloning method that relied on selection with a toxic lectin. Enzyme assays suggest that this sialyltransferase may contribute to sialyl Lewis $x$ synthesis.

53. Kurosawa $N$, Kawasaki $M$, Hamamoto $T$, Nakaoka $T$, Lee $Y$ $C$, Arita $M$, Tsuji S: Molecular Cloning and Expression of
Chick Embryo Gal $\beta 1,4 G l c N A c$ 2,6-sialyltransferase. Comparison with the mammalian enzyme. Eur $J$ Biochem 1994, 219:375-381.

54. Kitagawa $H$, Paulson JC: Cloning of a Novel $\boldsymbol{\alpha 2 , 3 - s i a l y l t r a n s - ~}$ -. ferase that Sialylates Glycoprotein and Glycolipid Carbohydrate Groups. / Biol Chem 1994, 269:1394-1401.

PCR cloning with sialyl motif primers was used to isolate the same sialyltransferase cDNA described in [52\%$]$. The substrate specificity described for this enzyme in this paper differs from the data reported in [52

55. Kurosawa N, Hamamoto T, Lee $\mathrm{Y}-\mathrm{C}$, Nakaoka T, Kojima N, -. Tsuji S: Molecular Cloning and Expression of GalNAc $\alpha 2,6$ sialyltransferase. I Biol Chem 1994, 269:1402-1409.

A chicken Gal NAc $\alpha 2,6$-sialyltransferase cDNA was isolated. This enzyme can form the sialyl Tn determinant.

56. Lee Y-C, Kojima N, Wada E, Kurosawa N, Nakaoka T, - Hamamoto T, Tsuji S: Cloning and Expression of a cDNÁ for a New Type of Gal $\beta 1,3$ GalNAc $\alpha 2,3$ sialyltransferase. ) Biol Chem 1994, 269:10028-10033.

This paper describes a novel cloned sialyltransferase cDNA. The substrate specificity of this enzyme is similar, but not identical, to the enzyme described in [51], and the tissue-specific expression patterns of their transcripts differ.

57. Seed B, Aruffo A: Molecular Cloning of the CD2 Antigen, the T-cell Erythrocyte Receptor, by a Rapid Immumoselection Procedure. Proc Natl Acad Sci USA 1987, 84:3365-3369.

58. Seed B: An LFA-3 cDNA Encodes a Phospholipid-linked Membrane Protein Homologous to its Receptor CD2. Nature 1987, 329:840-842.

59. Arurro A, Brian S: Molecular Cloning of a CD2B CDNA by a High-efficiency COS Cell Expression System. Proc Natl Acad SCi USA 1987, 84:8573-8577.

60. Mansour SL, Thomas KR, Capecchi MR: Disruption of the Proto-oncogene int-2 in Mouse Embryo-derived Stem Cells: a General Strategy for Targeting Mutations to Non-selectable Genes. Nature 1988, 336:348-352.

61. Capecchi MR: Targeted Gene Replacement. Sci Am 1994, 270:52-59.

62. Ioffe E, Stanley P: Mice Lacking N-acetylglucosaminyltrans-. ferase 1 Activity Die at Mid-gestation, Revealing an Essential Role for Complex or Hybrid $\mathbf{N}$-linked Carbohydrates. Proc Natl Acad Sci USA 1994, 91:728-732.

This is the first report of the 'knock-out' of a mouse glycosyltransferase gene. Mice homozygous for the null $\mathrm{N}$-acetylglucosaminyltransferase I allele lack complex and hybrid type N-glycosides, and die on day 11.5 of gestation.

63. Metzler M, Gertz A, Sarkar M, Schachter H, Schrader JW, - Marth ID: Complex Asparagine-linked Oligosaccharides are Required for Morphogenic Events During Post-implantation Development. $E M B O$; 1994, 13:2056-2065.

This is an independent report of an $\mathrm{N}$-acetylglucosaminyltransferase I 'knockout'. The phenotype is identical to that described in [62*0].

64. Lowe JB: Carbohydrate Recognition in Cell-Cell Interaction. Molecular Glycobiology. In Frontiers in Molecular Biology. Edited by Fukuda M. Oxford: Oxford University Press; 1994, in press.

65. Springer TA: Traffic Signals for Lymphocyte Re-circulation and Leukocyte Emigration: the Multi-step Paradigm. Cell 1994, 76:301-314.

66. Fukuda M, Spooncer E, Oates JE, Dell A, Klock JC: Structure of Sialylated Fucosyl Lactosaminoglycan Isolated from Human Granulocytes. I Biol Chem 1984, 259:10925-10935.

67. Yago K, Zenita K, Ginya H, Sawada M, Ohmori K, Okuma M,

- Kannagi $R$, Lowe JB: Expression of $\alpha-1,3$-fucosyltransferases which Synthesize Sialyl Lex and Sialyl Lea, the Carbohydrate Ligands for E- and P-selectins, in Human Malignant Cell Lines. Cancer Res 1993, 53:5559-5565.

This report catalogs the expression of four $\alpha-1,3$-fucosyltansferase genes in human cancer cell lines by Northern blot and reverse transcriptionPCR methods. 
68. Goelz S, Kumar R, Potvin B, Sundaram S, Brickelmaier $M$,

-. Stanley P: Differential Expression of an E-selectin Ligand (SLex) by two Chinese Hamster Ovary Cell Lines Transfected with the Same $\alpha-1,3$-fucosyltransferase Gene (ELFT). J Biol Chem 1994, 269:1033-1040.

These experiments demonstrate that Fuc-TIV-determined sialyl Lewis $\mathbf{x}$ expression depends upon the glycosylation phenotype of the host cell in which it is expressed.

69. Moore $\mathrm{KL}$, Stults NL, Diaz S, Smith DF, Cummings RD, Varki A, McEver RP: Identification of a Specific Glycoprotein Lig. and for P-selectin (CD62) on Myeloid Cells. J Cell Biol 1992, 118:445-456.

70. Sako D, Chang X-J, Barone KM, Vachino G, White HM, Shaw G, Veldman GM, Bean KM, Ahern T], Furie B, et al.: Expression Cloning of a Functional Glycoprotein ligand for P-selectin. Cell 1993, 75:1179-1186.

71. Leeuwenberg JFM, Tan A, Jeunhomme TMAA, Ploegh HL, Buurman WA: The Ligand Recognized by ELAM-1 on HL-60 Cells is Not Carried by $N$-linked Oligosaccharides. Eur $/$ Immunol 1991, 21:3057-3059.

72. Kojima N, Handa K, Newman W, Hakomori S-I: Inhibition of Selectin-dependent Tumor Cell Adhesion to Endothelial Cells and Platelets by Blocking $O$-glycosylation of these Cells. Biochem Biophys Res Commun 1992, 182:1288-1295.

73. Imai $Y$, Singer MS, Fennie C, Lasky LA, Rosen SD: Identification of a Carbohydrate-based Endothelial Ligand for a Lymphocyte Homing Receptor. J Cell Biol 1991, 113:1213-1221.

74. Lasky LA, Singer MS, Dowbenko D, Imai Y, Henzel WJ, Grimley C, Fennie C, Gillett N, Watson SR, Rosen SD: An Endothelial Ligand for L-selectin is a Novel Mucin-like Molecule. Cell 1992, 69:927-938.

75. Baumhueter S, Singer MS, Henzel $W$, Hemmerich $S$, Renz $M$, Rosen SD, Lasky LA: Binding of L-selectin to the Vascular Sialo Mucin, CD34. Science 1993, 262:436-438.

76. Haltiwanger RS, Kelly WG, Roquemore EP, Blomberg MA, Dong LY, Kreppel L, Chou TY, Hart GW: Glycosylation of Nuclear and Cytoplasmic Proteins is Ubiquitous and Dynamic. Biochem Soc Trans 1992, 20:264-269.

77. Hase S, Kawabata S, Nishimura $H$, Takeya $H$, Sueyoshi $T$ Miyata T, Iwanaga S, Takao T, Shimonishi $Y$, Ikenaka T: A New Tri-saccharide Sugar Chain Linked to a Serine Residue in Bovine Blood Coagulation Factors VII and IX. / Biochem 1988, 104:867-868.

78. Nishimura H, Kawabata S, Kisiel W, Hase S, Ikenaka T, Takao $T$, Shimonishi $Y$, Iwanaga $S$ : Identification of a Disaccharide $(X y l-G l c)$ and $a$ Trisaccharide $\left(x y l_{2}-G l c\right)$ aglycosidically linked to a Serine Residue in the First Epidermal Growth Factor-like Domain of Human Factors VII and IX and Protein Z and Bovine Protein Z. J Biol Chem 1989, 264:20320-20325.

79. Hase S, Nishimura $H$, Kawabata $S$, Iwanaga $S$, Ikenaka T: The Structure of (xylose) ${ }_{2}$ glucose-O-serine 53 Found in the First Epidermal Growth Factor-like Domain of Bovine Blood Clotting factor IX. / Biol Chem 1990, 265:1858-1861.

80. Nishimura H, Takao T, Hase S, Shimonishi $Y$, Iwanaga S: Human Factor IX has a Tetrasaccharide $O$-glycosidically Linked to Serine 61 Through the Fucose Residue. J Biol Chem 1992, 267:17520-17525.

81. Nishimura H, Yamashita S, Zeng Z, Walz DA, Iwanaga S: Evidence for the Existence of $O$-linked Sugar Chains Consisting of Glucose and Xylose in Bovine Thrombospondin. J Biochem 1992, 111:460-464.

82. Buko AM, Kentzer EJ, Petros A, Menon G, Zuiderweg ERP, Sarin VK: Characterization of a Post-translational Fucosylation in the Growth Factor Domain of Urinary Plasminogen Activator. ProC Natl Acad Sci USA 1991, 88:3992-3996.

83. Harris RJ, Leonard CK, Guzzetta AW, Spellman MW: Tissue Plasminogen Activator has an O-linked Fucose Attached to Threonine-61 in the Epidermal Growth Factor Domain. Biochemistry 1991, 30:2311-2314

84. Bjoern S, Foster DC, Thim L, Wiberg FC, Christensen $M$, Komiyama $\mathrm{Y}$, Pedersen AH, Kisiel W: Human Plasma and Recombinant Factor VII. Characterization of O-glycosylations at Serine Residues 52 and 60 and Effects of Sitedirected Mutagenesis of Serine 52 to Alanine. I Biol Chem 1991, 266:11051-11057.

85. Harris RI, Ling VT, Spellman MW: O-Linked Fucose is Present in the First Epidermal Growth Factor Domain of Factor XII but not Protein C. J Biol Chem 1992, 267:5102-5107.

86. Stults NL, Cummings RD: O-linked Fucose in Glycopro-

- teins from Chinese Hamster Ovary Cells. Glycobiology 1993, 3:589-596.

Detection of $O$-linked fucose residues in Chinese hamster ovary cells is reported. This observation suggests that $O$-linked fucose residues are widely distributed in mammalian cells.

87. Harris RJ, van Halbeek H, Glushka J, Basa LJ, Ling VT, Smith

- KJ, Spellman MW: Identification and Structural Analysis of the Tetrasaccharide NeuAca(2-6)Gal $\beta$ (1-4)GlcNAcb(1-3)Fuc $\alpha 1$ O-linked to Serine 61 of Human Factor IX. Biochemistry 1993, 32:6539-6547.

Structural determination of an $O$-fucose-type oligosaccharide on a human clotting factor is reported. These solid results clearly demonstrate the existence of this novel oligosaccharide moiety.

88. Kuraya N, Omichi K, Nishimura $H$, Iwanaga S, Hase S: Struc- tural Analysis of O-linked Sugar Chains in Human Blood Clotting Factor IX. / Biochem 1993, 114:763-765.

This group reported the same $O$-fucose type sugar chain, from the same

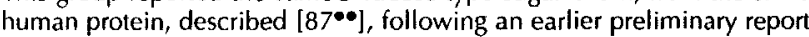
[80].

89. Stahl B, Klabunde T, Witzel $H$, Krebs B, Steup $M$, Karas $M$ Hillenkamp F: The Oligosaccharides of the Fe(III)-Zn(II) Purple Acid Phosphatase of the Red Kidney Bean. Determination of the Structure by a Combination of Matrix-assisted Laser Desorption/ionization Mass Spectrometry and Selective Enzymic Degradation. Eur / Biochem 1994, 220:321-330.

90. Billeci TM, Stults JT: Tryptic Mapping of Recombinant Proteins by Matrix-assisted Laser Desorption/ionization Mass Spectrometry. Anal Chem 1993, 65:1709-1716

91. Hase S, Ikenaka T: Estimation of Elution Times on Reversephase High-performance Liquid Chromatography of Pyridylamino Derivatives of Sugar Chains from Glycoproteins. Anal Biochem 1990, 184:135-138.

92. Hase S: Analysis of Sugar Chains by Pyridylamination. Methods Mol Biol 1993, 14:69-80.

S Natsuka and JB Lowe, Howard Hughes Medical Institute MSRB BI, Room 3510, University of Michigan Medical School, 1150 West Medical Center Drive, Ann Arbor, Michigan 481090650 , USA. 